DOI: $10.12731 / 2070-7568-2021-10-3-142-160$ УДК 338.2

\title{
ВЗАИМОСВЯЗЬ КЛАСТЕРОВ С КОНКУРЕНТОСПОСОБНОСТЬЮ РОССИИ
}

\section{Томашевская Ю.Н.}

В работе приведен экскурс по основным вехам кластерного развития Российской Федерачии. Проведен анализ влияния уровня кластерного развития на уровень конкурентоспособности Российской Федерации в 2010 и 2020гz. Дана оченка рейтингу Глобальной конкурентоспособности Всемирного экономического форума с позиции учета бизнес-среды территории, как основы формирования кластеров и реализачии кластерной политики. Высказаны предположения по предикторам, вызывающим данные нарушения и негативно влияюшим на дальнейший рост экономики на основе кластерной концеепии.

Цель - провести эмпирическое исследование и обнаружить точки взаимодействия кластеров с конкурентоспособностью экономики России.

Метод или методология проведения работы: в работе использованы методы анализа и синтеза, метод сравнительного анализа, а также статистические методы.

Результаты: систематизированы причины, препятствующие повышению индекса конкурентоспособности России. Предложены меры по их нивелированию, среди которых главная роль отводится вузам, как важнейшим участникам кластерного взаимодействия, деятельность которых должна быть направлена на повышение уровня ичифровизации образовательной среды, усиление инновационности компаний и самих университетов, повышение уровня привлекательности государственно-частного партнерства и др.

Область применения результатов: полученные результаты иуелесообразно применять органам государственной власти, отвечаю- 
щуим за эффективность реализации экономической политики России, одним из элементов которой является кластерная политика.

Ключевые слова: кластер; уровень конкурентоспособности; рейтинг глобальной конкурентоспособности; модель ромба; инновационное развитие; государственно-частное партнерство; конкуренция; цุифровизация

\section{INTERACTION OF CLUSTERS AND RUSSIAN COMPETITIVENESS}

\section{Tomashevskaya Y.N.}

The paper provides an excursion to the main milestones of the cluster development of the Russian Federation. The analysis of the influence of the level of cluster development on the level of competitiveness of the Russian Federation in 2010 and 2020 has been carried out. The rating of the Global Competitiveness of the World Economic Forum is assessed from the perspective of taking into account the business environment of the territory, as the basis for the formation of clusters and the implementation of cluster policy. Assumptions are made on the predictors that cause these violations and negatively affect the further growth of the economy on the basis of the cluster concept.

The goal: is to conduct an empirical study and discover the points of interaction of clusters with the competitiveness of the Russian economy.

Method or methodology of the work: methods of analysis and synthesis, the method of comparative analysis, as well as statistical methods were used in the work.

Results: the reasons hindering the increase of the Russian competitiveness index are systematized. Measures are proposed to level them, among which the main role is assigned to universities as the most important participants in cluster interaction, whose activities should be aimed at increasing the level of digitalization of the educational environment, enhancing the innovativeness of companies and universities themselves, increasing the attractiveness of public-private partnerships, etc. 
Field of application of the results: the results obtained should be applied to the state authorities responsible for the effectiveness of the implementation of the economic policy of Russia, one of the elements of which is the cluster policy.

Keywords: cluster; level of competitiveness; global competitiveness rating; diamond model; innovative development; public-private partnership; competition; digitalization

В Российской Федерации на протяжении не одного десятка лет реализуется целенаправленная политика по повышению уровня конкурентоспособности страны. Курс на обновление и формирование новой стратегии развития экономики был взят еще в 2006г., когда Центром стратегических разработок было поручено профессору Гарвардской школы бизнеса М. Портеру в соавторстве с его коллегами провести анализ российской экономики и ее конкурентоспособности с целью выработки рекомендаций и содействия планированию долгосрочной политики России [10].

Среди важных выводов, полученных в рамках данного исследования, была необходимость изменения комплексных и масштабных проблем в правовой, административной и образовательной сферах, переориентация в построении конкурентоспособности на добывающих отраслях на другие отрасли промышленности и развитие малых и средних предприятий, стимулирование долгосрочных инвестиций. Все это, как утверждал, М. Портер позволит в дальнейшем России стать инновационным, торговым и культурным центром.

В 2008 г. Правительством РФ была разработана Концепция долгосрочного социально-экономического развития Российской Федерации до 2020 года, установившая базовые принципы кластерной политики. В результате в стране возникло более 100 кластерных инициатив, половина из которых поддерживается в рамках различных государственной программ.

Среди наиболее важных документов, регламентирующих деятельность кластеров в России сегодня: 
- Методические рекомендации по реализации кластерной политики в субъектах Российской Федерации;

- Концепция долгосрочного социально-экономического развития Российской Федерации на период до 2020 года;

- Федеральный закон от 31 декабря 2014 № 488-Ф3 «О промышленной политике в Российской Федерации»;

- Постановление Правительства РФ от 31 июля 2015 г. № 779 «О промышленных кластерах и специализированных организациях промышленных кластеров»;

- Методические материалы по созданию промышленных кластеров (письмо Минпромторга России от 12.02.2016 № 7979/02).

Важным институтом поддержки (через оказание консультационных и организационных услуг, проведение маркетинговых исследований, разработку бизнес-планов и т.д.) развития кластерных инициатив и кластеров на территории российских регионов стали Центры кластерного развития, субсидии на создание которых, начиная с 2010 г., предоставляет Министерство экономического развития РФ.

С 2015 г. Министерство промышленности и торговли РФ начало реализацию программы по поддержке промышленных кластеров, что позволило выделить более 20 территориальных кластеров из нескольких десятков российских субъектов с более 500 участниками, которые субсидируются из федерального бюджета на возмещение до 50\% стоимости совместных проектов.

В 2016 г. был запущен проект «Развитие инновационных кластеров - лидеров инвестиционной привлекательности мирового уровня», который был направлен на создание точек опережающего роста, развитие инноваций и коммерциализацию технологий, рост экспорта высокотехнологичной продукции. В качестве основных задач в данном направлении на 2020г. Министерством экономического развития был обозначен мониторинг показателей развития кластеров за 2019 г. и актуализация «дорожных карт» по развитию 12 инновационных территориальных кластеров-лидеров [6]. 
Таким образом, можно заключить, что кластерный подход к развитию российской экономики был выбран в качестве одного из важных инструментов устойчивого развития и повышения конкурентоспособности страны, которая в 2010 г. занимала 63-е место среди 139 стран в рейтинге Индекса глобальной конкурентоспособности 2010-2011 гг. Изучим, каким образом проделанная работа смогла повлиять на конкурентоспособность России и какие остаются проблемные зоны, препятствующие эффективной реализации кластерной политики.

В начале анализа напомним, что между Индексом глобальной конкурентоспособности и уровнем кластерного развития установлена прямая зависимость (переменная «состояние кластерного развития» ${ }^{1}$ входит в состав одного из 12 контрольных показателей рейтинга), что позволяет рассматривать кластеры как один из ключевых факторов развития конкурентоспособных экономик.

Кроме того, следует заметить, что реализация кластерной концепции оказывает непосредственное воздействие на многие другие показатели индекса. В частности, в группе показателей «Инновационный потенциал» на «расходы на НИОКР в процентах от ВВП»; в группе показателей «Рынок продуктов» на «конкуренцию в сфере услуг» (профессиональные услуги (юридические услуги, бухгалтерский учет, инжиниринг, так далее.); розничные услуги; и сетевой сектор (телекоммуникации, коммунальные услуги, почта, транспорт и т. д.)); в группе «Навыки» на «легкость поиска квалифицированных сотрудников»; в группе «Финансовая система» на «финансирование малого и среднего бизнеса», а также «доступность венчурного капитала»; в группе «Динамика развития бизнеса» на «рост инновационных компаний» и «компании, внедряющие прорывные идеи».

${ }^{1}$ Основной вопрос, на который отвечает данная переменная: «Насколько широко в стране распространены хорошо развитые кластеры (географическая концентрация фирм, поставщиков, производителей сопутствующих товаров и услуг и специализированных учреждений в конкретной области)?». Оценка происходит в границах от 1 до 7, где 1 соответствует «не существует», а 7 - «широко распространено во многих областях». 
В свою очередь, согласно воззрениям М. Портера $[8,9]$, развитие кластеров находится в прямой зависимости от детерминант модели ромба ${ }^{2}$, каждый из которых в отдельности и все вместе способствуют достижению национального успеха или его провалу. То есть модель ромба - это бизнес-среда, в которой могут сформироваться кластеры.

Для доказательства взаимосвязи Рейтинга глобальной конкурентоспособности с моделью ромба установим соответствие между переменными Индекса и частями ромба, на которые они оказывают воздействие (таблица 1).

Рассматривая таблицу 1 , можно заключить, что все четыре из основных частей ромба задействованы в анализе при оценке уровня конкурентоспособности территории на основе Индекса глобальной конкурентоспособности. Группы показателей первой группы «Институты» и четвертой «Макроэкономическая стабильность» характеризуют часть ромба, вынесенную за его пределы - роль государства. Таким образом, данный рейтинг в полной мере оценивает качество национальной бизнес-среды и характеризует уровень развития различных частей кластера (ключевые компании, поставщики товаров и услуг, родственные и поддерживающие отрасли, органы государственной власти, научные и образовательные организации и др.).

В результате реализованных мер, согласно отчету о глобальной конкурентоспособности, уровень конкурентоспособности России в 2019 г. значительно увеличился (на 20 позиций) и составил 43 место $(66,7)$ из 141 страны. При этом очевидно (таблица 1), что достаточно слабые позиции прослеживались по группам показателей: «Здоровье», «Финансовая система» и «Рынок продуктов». Существенную уязвимость среди прочих переменных по-прежнему демонстрировала позиция, связанная именно с кластерным развитием государства - 101 место.

${ }^{2}$ Факторы ромба (факторные условия, родственные и поддерживающие отрасли, спрос на внутреннем рынке, стратегия фирм, их структура и конкуренция) обусловливают возникновение национальной среды, в которой компании зарождаются и обучаются конкурировать. Каждая из вершин ромба (и все вместе) иллюстрирует существенные составляющие для достижения успеха в конкуренции в международных масштабах [8, с. 175]. 
Таблицуа 1.

Соотношение групп показателей Индекса глобальной конкурентоспособности с их переменными, влияющими на развитие кластера

\begin{tabular}{|c|c|c|c|}
\hline $\begin{array}{c}\text { Группы } \\
\text { показателей }\end{array}$ & Переменная & $\begin{array}{l}\text { Часть } \\
\text { ромба }\end{array}$ & $\begin{array}{c}\text { Место } \\
\text { России } \\
\text { (рейтинг) }^{4} \\
\end{array}$ \\
\hline $\begin{array}{l}\text { 2. Инфра- } \\
\text { структура }\end{array}$ & Все переменные & $\begin{array}{l}\text { Факторные } \\
\text { условия }\end{array}$ & $50(74)$ \\
\hline $\begin{array}{l}\text { 3. Внедрение } \\
\text { ИКТ }\end{array}$ & Все переменные & $\begin{array}{l}\text { Факторные } \\
\text { условия }\end{array}$ & $22(77)$ \\
\hline 5. Здоровье & $\begin{array}{l}\text { Ожидаемая продолжительность здоро- } \\
\text { вой жизни }\end{array}$ & $\begin{array}{l}\text { Факторные } \\
\text { условия }\end{array}$ & 97 (69) \\
\hline 6. Навыки & $\begin{array}{l}\text { Легкость поиска квалифицированных } \\
\text { сотрудников }\end{array}$ & $\begin{array}{l}\text { Факторные } \\
\text { условия }\end{array}$ & $54(68)$ \\
\hline $\begin{array}{l}\text { 7. Рынок } \\
\text { продуктов }\end{array}$ & $\begin{array}{l}\text { Конкуренция в сфере услуг (професси- } \\
\text { ональные услуги (юридические услуги, } \\
\text { бухгалтерский учет, инжиниринг, так } \\
\text { далее.); розничные услуги; и сетевой } \\
\text { сектор (телекоммуникации, коммуналь- } \\
\text { ные услуги, почта, транспорт и т. д.) }\end{array}$ & $\begin{array}{l}\text { Родствен- } \\
\text { ные и } \\
\text { поддержи- } \\
\text { вающие от- } \\
\text { расли }\end{array}$ & $87(53)$ \\
\hline $\begin{array}{l}\text { 8. Рынок ра- } \\
\text { бочей силы }\end{array}$ & Все показатели & $\begin{array}{l}\text { Факторные } \\
\text { условия }\end{array}$ & $62(51)$ \\
\hline $\begin{array}{l}\text { 9. Финансо- } \\
\text { вая система }\end{array}$ & $\begin{array}{l}\text { - Финансирование малого и среднего } \\
\text { бизнеса; } \\
\text { - доступность венчурного капитала }\end{array}$ & $\begin{array}{l}\text { Факторные } \\
\text { условия }\end{array}$ & $95(56)$ \\
\hline $\begin{array}{l}\text { 10. Размер } \\
\text { рынка }\end{array}$ & $\begin{array}{l}\text { - Валовой внутренний продукт, оце- } \\
\text { ненный по паритету покупательной } \\
\text { способности; } \\
\text { - импорт товаров и услуг } \\
\end{array}$ & $\begin{array}{l}\text { Спрос на } \\
\text { внутреннем } \\
\text { рынке }\end{array}$ & $6(84)$ \\
\hline $\begin{array}{l}\text { 11. Динами- } \\
\text { ка развития } \\
\text { бизнеса }\end{array}$ & $\begin{array}{l}\text { - Рост инновационных компаний; } \\
\text { - компании, внедряющие прорывные } \\
\text { идеи }\end{array}$ & $\begin{array}{l}\text { Стратегия } \\
\text { фирм, их } \\
\text { структура и } \\
\text { конкурен- } \\
\text { ция } \\
\end{array}$ & $53(63)$ \\
\hline $\begin{array}{l}\text { 12. Иннова- } \\
\text { ционный по- } \\
\text { тенциал }\end{array}$ & $\begin{array}{l}\text { - Количество научных публикаций; } \\
\text { - количество патентных заявок; } \\
\text { - расходы на НИОКР, \% от ВВП. }\end{array}$ & $\begin{array}{l}\text { Факторные } \\
\text { условия }\end{array}$ & $32(53)$ \\
\hline
\end{tabular}

Другой публикуемый ежегодно доклад «Глобальный инновационный индекс», включающий обзор мировых тенденций в области

${ }^{3}$ Номер группы установлен в соответствии с Индексом глобальной конкурентоспособности.

${ }^{4}$ Согласно данным Индекса глобальной конкурентоспособности [19]. 
инноваций и рейтинг инновационной деятельности 131 страны мира также свидетельствует об неудовлетворительном развитии данного показателя в России. Так, в Рейтинге глобального инновационного развития за 2020г. [17] Россия по состоянию кластерного развития заняла только 95 место.

Из-за пандемии выпуск Отчета Всемирного экономического форума за 2020г. осуществлен не был. Но в декабре 2020 года вышло специальное издание «Доклад о глобальной конкурентоспособности, специальный выпуск 2020: Как страны продвигаются на пути к выздоровлению» [19], из которого следует, что наиболее уязвимыми, влияющими на развитие кластеров, пока для России являются такие зоны, как:

- готовность модернизировать инфраструктуру в целях ускоренной трансформации в энергетике, а также расширения доступа к электроэнергии и ИКТ;

- конкуренция и антимонопольные рамки, необходимые в период четвертой промышленной революции, для обеспечения доступа к рынкам как на местном, так и на международном уровне;

- содействие созданию «рынков завтрашнего дня», особенно в областях, требующих сотрудничества между государственным и частным секторами;

- стимулирование и расширение инвестиций в исследования, инновации и изобретения, которые могут создать новые «рынки завтрашнего дня»;

- следование государственными учреждениями строгих принципов управления и построение долгосрочного видения и завоевание доверия, служа своим гражданам;

- обновление учебных программ и увеличение инвестиций в навыки, необходимые для работы и «рынков завтрашнего дня».

Данные результаты отчасти коррелируют с результатами российского Индекса готовности к будущему [12], в задачи которого в том числе входит анализ конкурентоспособности стран по ряду экономических политических и других показателей. Минимальное 
количество баллов России в 2019 г. наряду с другими показателями приходилось на группу показателей «Экономика» (0,18 балла), включающую такие статистические индикаторы, как: доля затрат на НИОКР; доля инновационной продукции; экспорт технологий hi-tech; место национальной команды в ассоциации WorldSkills и др.

Следовательно, можно заключить, что для достижения высокого уровня развития Российская Федерация испытывает нехватку в соответствующих образовательных программах, недостаточное развитие инфраструктуры, недостаточный уровень конкуренции, низкий уровень инвестиций в инновации, недостаточный уровень развития государственно-частного партнерства. Отметим, что все обозначенные факторы относятся к зонам воздействия и стимулирования посредством эффективной реализации кластерного подхода в сочетании с эффективной макроэкономической политикой государства.

Попытаемся изучить причины, обусловившие такое положение ситуации и снижение обозначенных показателей.

Отставание по критерию «уровень развития государственно-частного партнерства» является закономерным ввиду особенностей исторического политического и экономического тренда развития России. Так, по сравнению с другими, преимущественно западными, странами Россия официальный статус механизма государственно-частного партнерства получила лишь в начале этого столетия в рамках утвержденных Правительством РФ «Основных направлений деятельности Правительства РФ на период до 2008 года» от 28 июля 2004 г. В данном документе развитию государственно-частного партнерства посвящен пункт 6 в подразделе «Повышение уровня жизни населения, содействие развитию человеческого капитала» раздела «О приоритетных направлениях социально-экономической политики» [11].

Также можно предположить, что на современном этапе недостаточно высокий уровень государственно-частного партнерства обусловлен отсутствием мотивации со стороны бизнеса, низким уровнем его доверия к власти. Для подтверждения данной гипотезы обратимся к данным рейтинга Всемирного банка «Качество государственного управления в странах мира» [21] (таблица 2). 
Таблицуа 2.

Состояние институциональной среды в России (процентальный ранг) ${ }^{5}, 2019 г^{6}{ }^{6}$

\begin{tabular}{|c|c|c|c|c|c|}
\hline $\begin{array}{c}\text { Качество } \\
\text { законода- } \\
\text { тельства }\end{array}$ & $\begin{array}{c}\text { Учёт мнения на- } \\
\text { селения и подот- } \\
\text { сётнсть государ- } \\
\text { ствнных органов }\end{array}$ & $\begin{array}{c}\text { Политическая } \\
\text { стабильность } \\
\text { и отсутствие } \\
\text { насилия }\end{array}$ & $\begin{array}{c}\text { Эффектив- } \\
\text { ность рабо- } \\
\text { ты прави- } \\
\text { тельства }\end{array}$ & $\begin{array}{c}\text { Вер- } \\
\text { ховен- } \\
\text { ство } \\
\text { закона }\end{array}$ & $\begin{array}{c}\text { Сдержи- } \\
\text { вание } \\
\text { корруп- } \\
\text { ции }\end{array}$ \\
\hline 36,06 & 18,23 & 25,71 & 58,17 & 25,0 & 21,63 \\
\hline
\end{tabular}

Из данных таблицы 2 следует, что Россия имеет достаточно низкие баллы по всем показателям рейтинга, что свидетельствует о низкой оценке качества и эффективности государственного управления со стороны экспертов, предпринимателей и граждан, что формирует в свою очередь, отрицательный образ органов государственной власти, как партнера при реализации совместных инициатив ${ }^{7}$.

Для установления причин невысокого уровня конкуренции в РФ воспользуемся результатами онлайн-опроса представителей российского бизнеса, проведенного в 2019г. аналитическим центром при Правительстве Российской Федерации [3]. Так, при оценке общего состояния конкуренции и конкурентной среды на российских рынках было установлено, что:

- рост числа конкурентов продолжает снижаться: 47\% в 2019 году против 48\% в 2018 году и 49\% в 2017 году (при этом

${ }^{5}$ Процентильный ранг (0-100) указывает рейтинг страны среди всех стран мира. 0 соответствует низшему рангу, а 100 соответствует высшему рангу.

${ }^{6}$ Составлено на основе данных Всемирного банка http://info.worldbank.org/ governance/WGI. В рейтинге участвуют около 200 стран.

${ }^{7}$ Факт недоверия к органам государственной власти, в том числе из-за непрозрачности нормативно-правовой, базы как одной из причин недостаточности развития государственно частного партнерства в России, также рассматривается в следующих научных работах: Кохановская, Петин; Амирова; Бродунов, Булычева; Berger R. et al.; Barkhatov V., Benz D., Pletnev D. и др. При этом последнее упомянутое исследование показало тесную корреляцию между некоторыми индексами доверия, уверенности и экономическими показателями, характеризующими состояние национальной экономики. Интересными выводами данной работы стало доказательство существования связи между доверием и долей инновационных предприятий в стране, а также утверждение о том, что доверие является скорее следствием, чем условием экономического роста (то есть доверие следует рассматривать как результат экономических изменений в стране). 
доля участников, отметивших снижение числа конкурентов, остается стабильно высокой при проведении данного опроса - более $20 \%$ (в 2019 году - 23\%));

- основными причинами снижения числа конкурентов, по мнению респондентов, (в соответствии со степенью значимости) являются: действия органов власти, направленные на снижение конкуренции, уход российских компаний с рынка, изменения в нормативно-правовой базе, регулирующей деятельность предпринимателей;

- снижение затрат на производство и реализацию продукции и услуг является наиболее популярным способом повышения конкурентоспособности (61\%), далее обучение персонала $(47 \%)$ и новые маркетинговые стратегии (43\%);

- только $36 \%$ респондентов указали, что считают конкуренцию полезной для развития бизнеса;

- слабую конкуренцию испытывают представители топливноэнергетического комплекса, сферы производства и распределения газа, электроэнергии, воды, химической промышленности, здравоохранения и социальной сферы;

- среди серьезных барьеров для развития бизнеса респонденты выделили: высокие налоги, нестабильность российского законодательства в отношении регулирования деятельности предприятий, сложность доступа к финансовым ресурсам и недостаток квалифицированных кадров;

- приобретение технологий, патентов, лицензий, ноу-хау за последние три года осуществило 10\% микропредприятий, 3,7\% представителей малого бизнеса и $2,8 \%$ среднего и крупного бизнеса;

- $42 \%$ респондентов продолжают считать, что органы государственной власти мешают бизнесу своими действиями и инициативами.

Вместе с тем, есть и положительные моменты:

- увеличение доли использования различных способов повышения собственной конкурентоспособности: 80\% компаний использовали не менее двух инструментов, в противовес 77\% 2018 г;;

- в отдельных отраслях в качестве конкурентного преимущества использовалась покупка машин и технологического обо- 
рудования: $80 \%$ производителей в сфере пищевых продуктов, $72 \%$ - в металлургической промышленности; $71 \%$ - в отрасли сельского хозяйства;

- 65-68\% производителей электронного и оптического оборудования, машин и оборудования осуществляли свои собственные НИОКР (при этом самостоятельное проведение НИОКР за последние три года осуществило лишь 20\% респондентов, из них 12,9\% - представители микропредприятий, 3,7\% - малый бизнес, 2,8\% - средний и крупный бизнес);

- приобретением технологий, патентов, лицензий, ноу-хау в 2019 году наиболее воспользовались: в сфере образования - 36\%.

Результаты данного опроса позволяют не только лучше понять причины, препятствующие развитию конкуренции, но и подтверждают следующий барьер на пути развития инновационной (равно высококонкурентоспособной) экономики России - низкий уровень вложения инвестиций в инновации со стороны бизнеса. Поскольку конкуренция и инновационность компаний являются взаимосообщающимися сосудами (что убедительно представлено в работах М. Портера [7, 8, 9], а также доказано в ряде практических исследований, посвященных анализу взаимосвязи конкурентоспособности компаний и их инновационных процессов $[13,14])$, снижение конкуренции, отмечаемое многими участниками опроса, отрицательно сказалось на желании бизнеса вкладываться в инновационные разработки, являющиеся основой роста производительности компаний и увеличения благосостояния населения, что к конечном итоге ведет к развитию конкурентоспособной экономики.

В связи с обозначенным выше к реализации предлагается ряд мероприятий, направленных на повышение уровня кластеризации экономики РФ.

Во-первых, необходимо усовершенствовать условия по развитию инновационной экосистемы страны, как комплекса факторов, необходимого для эффективного взаимодействия науки и бизнеса в целях развития инноваций, коммерциализации НИОКР и формирования новых конкурентных преимуществ ${ }^{8}$. Университеты в данном случае должны рассматриваться не только в качестве центров подготовки 
высококвалицированных кадров, но в качестве драйверов развития инновационного развития кластеров и территорий 9 .

Это, в свою очередь, предполагает выход на новый уровень взаимодействия вузов с промышленными партнерами в направлении поиска новых технологических и технических решений и форм коммерциализации результатов интеллектуальной деятельности вузов ${ }^{10}$; формирование предпринимательского мышления у слушателей программ магистратур (как управляющего контура кластера и участников основных производственных элементов кластера) таких направлений, как «Финансы и кредит», «Банки и банковская деятельность», «Государственное и муниципальное управление» посредством реализации курсов (дисциплин) по основам конкурентоспособности и кластерного развития. Такой опыт успешно реализуется по программам государственного и муниципального управления в Дагестанском Государственном Университете, Томском Государственном Педагогическом Университете, Московском городском университете управления Правительства Москвы и др., но единично представлен для программ, связанных с предпринимательством, например, в Астраханском государственном университете.

Говоря о обновлении образовательной составляющей, нельзя не отметить необходимость изменения российскими вузами рабочих программ в связи такими неизбежными тенденциями на рынке труда, как роботизация и искусственный интеллект. В этой связи актуальными при формирования новых специалистов становятся навыки в сфере цифровых технологий, анализа данных, новаторства, STEM навыки. И хотя пандемия потребовала срочного перехода к цифровизации

\footnotetext{
${ }^{8}$ С данной позицией согласна Кузнецова Н.Г. в соавторстве с коллегами [18], которая при этом отмечает, что эффективность функционирования такой региональной инновационной системы во многом будет зависеть от уровня взаимодействия всех ее субъектов, реализуемого через информационный обмен и другие экономические ресурсы при реализации совместных инновационных проектов.

${ }^{9}$ Например, Д. Джоу [22] включает в состав функций университетов в инновационном кластере: производство знаний, распространение знаний и пропаганду инновационной культуры.

${ }^{10} \mathrm{~B}$ том числе необходима разработка механизмов создания межуниверситетского знания при реализации совместных инновационных проектов на уровне региона (пока в рамках российских кластеров в основном практикуются случаи частного взаимодействия вузов с конкретными предприятиями промышленности или кластером).
} 
как российского общества в целом, так и сферы образования, наша страна присоединилась к этому тренду позже большинства других развитых стран мира, а, следовательно, находится в догоняющей позиции и вузам необходимо проделать работу на опережение в вопросах целостного освоения, усвоения и трансляции новых требуемых на рынке труда «завтрашнего дня» навыков и компетенций.

Так же сравнительные исследования инновационной политики наиболее развитых стран показывают, что совершенствование научной инновационной системы в значительной степени зависит от эффективности работы ее институтов [1]. То есть для развития механизма взаимодействия бизнеса и государства требуется разработка и внедрение новых национальных стратегий поддержки инновационного сектора экономики, в том числе за счет повышения инвестиционной привлекательности территорий, венчурного инвестирования и реализации инновационных инициатив по принципу научно-исследовательского партнерства при активном участии региональных (местных) органов власти.

Кроме того необходимым является стимулирование межфирменной конкуренции за счет формирования «правильного» предпринимательского мышления, снижения уровня зарегулированности отдельных сфер экономки, снижение уровня государственного участия, например, в энергетическом комплексе, банковском секторе, сфере здравоохранения и др., уменьшения бюрократических барьеров и повышение нестабильности российского законодательства в области развития малого и среднего бизнеса, проведения ежегодной оценки уровня конкуренции в отраслях экономики регионов, в том числе имеющих предпосылки к формированию кластеров.

Подведя итог, отметим, что за прошедшее десятилетие повестка, связанная с реализацией кластерной политики, заняла важное место в программе действий российского правительства. В результате данных мероприятий было определено 20 субъектов Российской Федерации с 22 кластерами на их территории (в том числе два межрегиональных кластера) с более чем 500 участниками. И хотя проделанная работа принесла ощутимые плоды как для субъектов Российской Федерации, так и 
для экономики страны в целом, существующий на мезо- и макроуровне ряд препятствий требует пристального внимания для устранения разрыва между различными экономическими системами и обеспечения социально-экономической устойчивости российской экономики. Данное исследование позволило определить приоритеты по приложению усилий в ближайшей перспективе как со стороны органов государственной власти, так со стороны вузов, как важнейшего участника кластерного взаимодействия, роль которого в развитии кластеров в связи с последними тенденциями на мировом рынке только усиливается.

\section{Список литературы}

1. Акопян А.Р. Роль кластеров в развитии современных национальных инновационных систем субъектов мирового хозяйства: диссертация на соискание ученой степени кандидата экономических наук. М., 2016. $166 \mathrm{c}$.

2. Амирова А.А. Проблемы развития государственно-частного партнерства в РФ на современном этапе // Материалы конференции «Северный Кавказ: пространственное развитие и человеческий капитал». Пятигорск, 2018. С. 22-26.

3. Аналитический центр при Правительстве Российской Федерации. Оценка состояния конкурентной среды в России, 2019. https:/ac.gov. $\mathrm{ru} /$ archive/files/publication/a/21420.pdf

4. Бродунов А.Н., Булычева К.И. Проблемы развития государственночастного партнерства в РФ на современном этапе // Вестник Московского университета имени С. Ю. Витте. Серия 1: Экономика и управление. 2017. № 1 (20), С. 84-88.

5. Кохановская И.И., Петин А.А. Проблемы развития государственночастного партнерства в Российской Федерации // Управление. 2018. № 3(21) / 90, С. 34-39.

6. Министерство экономического развития РФ. Развитие кластеров - лидеров инвестиционной привлекательности мирового уровня. https://www.economy.gov.ru/material/departments/ d01/razvitie_sistemy_gosudarstvennoy_podderzhki_innovaciy_v_ subektah/klastery/ 
7. Портер М. Конкурентное преимущество. Как достичь высокого результата и обеспечить его устойчивость. Москва: Альпина Паблишер, 2019. 945 c.

8. Портер М. Конкуренция. Москва: Вильямс, 2005. 608 с.

9. Портер М. Международная конкуренция. Конкурентные преимущества стран. Москва: Альпина Паблишер, 2020. 947 с.

10. Портер М., Кетелс К., Дельгадо М., Брайден Р. Конкурентоспособность на распутье: направления развития российской экономики. http://www.sp-ved.narod.ru/MATERS/PORTER_RFstrategy.pdf

11. Постановление Правительства «Основные направления деятельности Правительства Российской Федерации на период до 2008 года» от 28 июля 2004 г. https://docs.cntd.ru/document/902130221.

12. Совместный проект Международного дискуссионного клуба «Валдай» и ВЦИОМ. Индекс готовности к будущему, 2019. https:// ru.valdaiclub.com/files/29386

13. Agustine A.A., Ssemugenyi F. The Relationship between Innovation Strategies and Organizational Competitiveness of Kenya Power \& Lighting Company Ltd. // Global Journal of Interdisciplinary Social Sciences. 2014. Vol. 3, No. 4. P. 36-40.

14. Arvanitis S., Loukis E. Information and Communication Technologies, Human Capital, Workplace Organization and Labour Productivity in Greece and Switzerland: A Comparative Study Based on Firm-level Data // Information Economics and Policy. 2009. Vol. 21. P. 43-61.

15. Barkhatov V., Benz D., Pletnev D. Trust in the Russian economy and business environment // E3S Web of Conferences. 2020. Vol. 210, 13013. 10 p. https://doi.org/10.1051/e3sconf/202021013013

16. Berger R., Herstein R., Silbiger A., Barnes B. Developing international business relationships in a Russian context // Management International Review. 2017. Vol. 57 (3). P. 441-471.

17. Cornell University, INSEAD, and WIPO. The Global Innovation Index 2020: Who Will Finance Innovation? Ithaca, Fontainebleau and Geneva, 2020. https://www.wipo.int/edocs/pubdocs/en/wipo_pub_gii_2020.pdf

18. Kuznetsov N.G., Rodionova N.D., Ponomareva M.A., Tyaglov S.G. Assessing Level of Interaction between Subjects of Innovative Systems 
within Russian Regions // European Research Studies Journal. 2017. Vol. XX, Iss. 3B. P. 355-368.

19. Schwab K. Global competitiveness report. World Economic Forum. 2019. https://www3.weforum.org/docs/WEF_TheGlobalCompetitivenessReport2019.pdf

20. Schwab K., Zahidi S. Global Competitiveness Report Special Edition 2020: How Countries are Performing on the Road to Recovery. World Economic Forum, 2020. https://www3.weforum.org/docs/WEF TheGlobalCompetitivenessReport2020.pdf

21. World governance indicator. http://info.worldbank.org/governance/WGI 22.Zhou, D. The Research on the Functions of Universities in an Innovation Cluster and the Realization Mechanisms // Open Journal of Business and Management. 2017. Vol. 5. No. 1. P. 63-72. https://doi.org/10.4236/ ojbm.2017.51006

\section{References}

1. Akopyan A.R. Rol' klasterov v razvitii sovremennykh natsional'nykh innovatsionnykh sistem subektov mirovogo khozyaystva [The role of clusters in the development of modern national innovation systems of subjects of the world economy]. M., 2016, 166 p.

2. Amirova A.A. Problemy razvitiya gosudarstvenno-chastnogo partnerstva $\mathrm{v}$ RF na sovremennom etape [Problems of the development of public-private partnership in the Russian Federation at the present stage]. Materialy konferentsii «Severnyy Kavkaz: prostranstvennoe razvitie $i$ chelovecheskiy capital» [Materials of the conference "North Caucasus: spatial development and human capital']. Pyatigorsk, 2018, pp. 22-26.

3. Analytical Center for the Government of the Russian Federation. Assessment of the state of the competitive environment in Russia, 2019. https://ac.gov.ru/archive/files/publication/a/21420.pdf

4. Brodunov A.N., Bulycheva K.I. Vestnik Moskovskogo universiteta imeni S. Yu. Vitte. Seriya 1: Ekonomika i upravlenie, 2017, no. 1 (20), pp. 84-88.

5. Kokhanovskaya I.I., Petin A.A. Upravlenie, 2018, no. 3(21)/90, pp. 34-39.

6. Ministry of Economic Development of the Russian Federation. Development of clusters - leaders in investment attractiveness of the world level. 
https://www.economy.gov.ru/material/departments/d01/razvitie_sistemy_gosudarstvennoy_podderzhki_innovaciy_v_subektah/klastery/

7. Porter M. Konkurentnoe preimushchestvo. Kak dostich'vysokogo rezul'tata i obespechit' ego ustoychivost' [Competitive advantage. How to achieve a high result and ensure its sustainability]. Moscow: Al'pina Pablisher, 2019, 945 p.

8. Porter M. Konkurentsiya [Competition]. Moscow: Vil'yams, 2005, 608 p.

9. Porter M. Mezhdunarodnaya konkurentsiya. Konkurentnye preimushchestva stran [International competition. Competitive advantages of the countries]. Moscow: Al'pina Pablisher, 2020, 947 p.

10. Porter M., Ketels K., Del'gado M., Brayden R. Konkurentosposobnost'na rasput'e: napravleniya razvitiya rossiyskoy ekonomiki [Competitiveness at the Crossroads: Directions of Development of the Russian Economy]. http://www.sp-ved.narod.ru/MATERS/PORTER_RFstrategy.pdf

11. Resolution of the Government "Main directions of activities of the Government of the Russian Federation for the period up to 2008" dated July 28, 2004. https://docs.cntd.ru/document/902130221.

12. Joint project of the Valdai International Discussion Club and VTsIOM. Future Readiness Index 2019, 2019. https://ru.valdaiclub.com/files/29386

13. Agustine A.A., Ssemugenyi F. The Relationship between Innovation Strategies and Organizational Competitiveness of Kenya Power \& Lighting Company Ltd. Global Journal of Interdisciplinary Social Sciences, 2014, vol. 3, no. 4, pp. 36-40.

14. Arvanitis S., Loukis E. Information and Communication Technologies, Human Capital, Workplace Organization and Labour Productivity in Greece and Switzerland: A Comparative Study Based on Firm-level Data. Information Economics and Policy, 2009, vol. 21, pp. 43-61.

15. Barkhatov V., Benz D., Pletnev D. Trust in the Russian economy and business environment. E3S Web of Conferences, 2020, vol. 210, 13013. 10 p. https://doi.org/10.1051/e3sconf/202021013013

16. Berger R., Herstein R., Silbiger A., Barnes B. Developing international business relationships in a Russian context. Management International Review, 2017, vol. 57 (3), pp. 441-471.

17. Cornell University, INSEAD, and WIPO. The Global Innovation Index 2020: Who Will Finance Innovation? Ithaca, Fontainebleau and 
Geneva, 2020. https://www.wipo.int/edocs/pubdocs/en/wipo_pub_ gii_2020.pdf

18. Kuznetsov N.G., Rodionova N.D., Ponomareva M.A., Tyaglov S.G. Assessing Level of Interaction between Subjects of Innovative Systems within Russian Regions. European Research Studies Journal, 2017, vol. XX, no. 3B, pp. 355-368.

19. Schwab K. Global competitiveness report. World Economic Forum. 2019. https://www3.weforum.org/docs/WEF_TheGlobalCompetitivenessReport2019.pdf

20. Schwab K., Zahidi S. Global Competitiveness Report Special Edition 2020: How Countries are Performing on the Road to Recovery. World Economic Forum, 2020. https://www3.weforum.org/docs/WEF_TheGlobalCompetitivenessReport2020.pdf

21. World governance indicator. http://info.worldbank.org/governance/WGI 22.Zhou, D. The Research on the Functions of Universities in an Innovation Cluster and the Realization Mechanisms. Open Journal of Business and Management, 2017, vol. 5, no. 1, pp. 63-72. https://doi.org/10.4236/ ojbm.2017.51006

\section{ДАННЫЕ ОБ АВТОРЕ}

Томашевская Юлия Николаевна, доцент кафедры мировой экономики и финансов, кандидат экономических наук, доцент Астраханский государственный университет

ул. Татищева, 20A, г. Астрахань, Астраханская область, 414056, Российская Федеращчи

ylia_tom@mail.ru

\section{DATA ABOUT THE AUTHOR}

Yulia N. Tomashevskaya, Associate Professor of the Department of World Economy and Finance, Candidate of Economic Sciences, Associate Professor

Astrakhan State University

20A, Tatishchev Str., Astrakhan, Astrakhan region, 414056, Russian Federation

ylia_tom@mail.ru

ORCID: 0000-0001-8743-2452 